\title{
THE EFFICIENCY OF THE ECTOPARASITOID Diglyphus isaea WALKER (HYMENOPTERA: EULOPHIDAE) ON THE SERPENTINE LEAFMINER Liriomyza trifolii (BURGESS) IN TOMATO GREENHOUSES .
}

Kassem, S. A. A.; R. I. E. Magouz and A. R. El-khouly

Sakha Agric. Res. Station, Plant Protection Res. Inst., Agric. Res. Center, Egypt.

\begin{abstract}
Natural abundance of the ectoparasitoid Diglyphus isaea Walker was studied in four tomato greenhouses at Sakha, Mehalla Al-Kobra, and Metobus. The parasitoid showed low populations in March, then developed good populations that kept the populations of the serpentine leafminer, Liriomyza trifolii at low densities till the end of the season in all studied greenhouses.

$D$. isaea recorded two peaks of abundance in three of the greenhouses, the highest peak recorded 21,36, 28 and 31 individuals/ 50infested leaflets in greenhouses 1,2, 3 and 4 , respectively. The highest average numbers occurred in April in all greenhouses recording $18 \pm 2.9,24.3 \pm 8.3,23.0 \pm 5.2$ and $26.0 \pm 5.2$ individuals/ 50infested leaflets in greenhouses $1,2,3$ and 4 ,respectively. On the other hand, the percentage of parasitism ranged between $17.8 \pm 0.9$ and $47.3 \pm 1.3 \%$ recording its highest numbers in May in greenhouse 1 (43.3 $\pm 5.3 \%$ ), and in April in greenhouses, 2,3 and 4 recording $46.4 \pm 5.1,43.6 \pm 2.3$ and $47.3 \pm 1.3 \%$, respectively. The percentage of killed larvae according to host-feeding recorded its highest monthly average numbers in May in greenhouses 1, 2 and $3(43.5 \pm 5.3,29.0$ \pm 9.2 and $24.0 \pm 7.3 \%$ respectively) and in June in greenhouse 4 recording $30.6 \pm$ $6.4 \%$.
\end{abstract}

\section{INTRODUCTION}

Genus Liriomyza contains more than 300 species, widely distributed in the new and old world but are commonly found in temperate areas (Parrella, 1987). Among them, L. trifolii Burgess (Diptera: Agromyzidae), the American serpentine leaf miner is known as one of the most serious pests of many vegetable and horticultural crops worldwide (Spencer, 1973). L. trifolii has a wide range of host plants with more than 400 species reported as hosts (Baufeld and Motte, 1992). Thirty nine species of parasitoids have been reported to attack $L$. trifolii on a variety of commodities (Johnson and Hara, 1987). Diglyphus isaea Walker was the most dominant parasitoid species against $L$. trifolii of the parasitoid complex which contained Opius pallipes Wesmeal and Chrysocharis parksi Crawford (Hymenoptera: Eulophidae) as endoparasitoids (El-Khouly, 2003). Ozawa et al. (2001) found that the dominant parasitoid species emerging from L.trifolii larvae in Homaoka tomato greenhouses was D.isae.This parasitoid was released in tomato greenhouses to control L.trifolii at different release doses, the percentage of parasitism ranged $94.1-100 \%$ by the end of the growing season (Ozawa et al 1999and Ozawa et al 2001). The parasitoid D.isae is a primary ectoparasitoid capable of developing on at least 18 different agromyzid species (Boueck 
and Askew, 1968). Goncalves and Almeida (2005) reported that the survey conduted on several protected crops showed that two ectoparastiods of Liriomyza spp; D.isaea and D.poppoe have been found every year, reaching rate of parasitism of $80-85 \%$ with predominance of the first one.Among the parasitoid complex of Liriomyza spp.in the Iranian fauna which contained several parasitoid species, the Eulophid D.isaea was the most common one (Asadi et al. 2006)

From the available literature, few authors have studied the role of the parasitoid D.isaea as biocontrol agent against $L$. trifolii in tomato fields in Egypt (Awadalla and Fathy 1998 , Awadalla et al.2008 and Khouly, 2009) but rarely in tomato greenhouses. Therefore, the present investigation was undertaken to study the role of the parasitoid $D$. isaea in tomato greenhouses.

\section{MATERIALS AND METHODS}

The present study was carried out at four districts; Sakha, Mehalla, AL-Kobra,Desouk and Metobus from March to June 2009. One tomato greenhouse $\left(500 \mathrm{~m}^{2}\right)$ in each location was planted with 30- day old tomato nurslings. One week after transplanting, samples of the greenhouses were taken weekly. Fifty tomato leaflets infested with L. trifolii were taken from each greenhouse. Samples were kept in plastic bags and transferred to be examined in the laboratory .Number of living L. trifolii larvae, immature stages of the ectoparasitoid Diglyphus isaea and number of dead larvae according to feeding ( no ovipositon) were counted and recorded. Normal agricultural practices of fertilizing and irrigation were followed and no chemical control measurements were applied .

\section{RESULTS AND DISCUSSION}

Data presented in fig. (1.1) shows the numbers of the ectoparasitoid $D$. isaea and the percentage of parasitism at sakha location. The parasitoid, $D$. isaea recorded low numbers at the beginning of the season in late march and early April, then the population increased recording two peaks of abundance (21 and 13 individuals/50 infested leaflets) on $13^{\text {th }}$ of April and the $1^{\text {st }}$ of June, respectively. On the other hand, the percentage of parasitism ranged between 24.0 and $52.9 \%$ and recorded $50 \%$ at the end of the season.

At Mehalla AL- Kobra greenhouse (Fig. 1.2) the population of $D$. isaea recorded two peaks of abundance (36 and 13 individuals /50infested leaflets) on $20^{\text {th }}$ of April and $18^{\text {th }}$ of May, respectively, while the percentage of parasitism ranged between 15.8 and $51.3 \%$ and also recorded $50 \%$ at the end of the season .

At Desouk (Fig.1.3), the population of $D$. isaea recorded two peaks of abundance ( 28 and 14 individuals/50infested leaflets) on $13^{\text {th }}$ of April and $18^{\text {th }}$ of May, respectively, while the percentage of parasitism ranged between 26.9 and $54.5 \%$ and recorded $54.5 \%$ at the end of the season. 
At Metobus (Fig.1.4), the population of $D$. isaea recorded three peaks of abundance $\left(31,21\right.$ and 20 individuals/50infested leaflets) on $13^{\text {th }}$ of April, $27^{\text {th }}$ of April and $25^{\text {th }}$ of May respectively, while the percentage of parasitism ranged between (22.5 and 58.3\%) and reached $58.3 \%$ at the end of the season .

It could be reported that, the percentage of natural parasitism by $D$. isaea reached about $50 \%$ in all studied greenhouses thus, it seems that no need to release the parasitoid in such greenhouses. Similar results were obtained by El-khouly(2009) who found that the percentage of parasitism by $D$. isaea in tomato greenhouses ranged between 10.3 and $55.3 \%$ when no release treatments were applied. Studies of Awadalla et al.2009 and ELKhouly, 2009 revealed that $D$. isaea had high rates of parasitism on L. trifolii in open fields. They indicated that the parasitoid slightly preferred cowpea and kidney bean than tomatoes.

As shown in Table (1) the parasitoid $D$. isaea showed its highest monthly average numbers in April in the four greenhouses recording (18.0 \pm $2.9,24.3 \pm 8.3,23.0 \pm 5.2$ and $26.0 \pm 5.2$ individuals/50 infested leaflets) at Sakha, Mehalla AL-Kobra, Desouk and Metobus, respectively. On the other hand monthly average percentage of parasitism recorded its highest numbers in June (49.8 $\pm 3.2 \%$ ) in location (1) and in April in locations 2, 3 and 4 recording $46.4 \pm 5.1,43.6 \pm 2.3$ and $47.3 \pm 1.3 \%$, respectively. Monthly average percentages of dead larvae according to host-feeding (no oviposition) recorded its highest numbers in May in greenhouses 1, 2 and 3 recording $43.5 \pm 5.3,29.0 \pm 9.2$ and $24.0 \pm 7.3 \%$ respectively, and in June in greenhouse (4) recording $30.6 \pm 6.4 \%$.

Theses results show that that the larval ectopoarasitoid, $D$. isaea recorded its highest average numbers in April when the host, L. trifolii reached high population because $D$. isaea prefers the high population of its host (Linden 1993). On the other hand, the monthly average percentages of killed larvae according to host-feeding ranged between $(17.8 \pm 0.9$ and $47.3 \pm 1.3 \%$ ). Data presented by EL- Khouly, 2009 showed that $D$. isaea females killed $21.3 \pm 4.7 \%$ of $L$. trifolii larvae, $9.6 \pm 3.7$ of them were host fed and 12.3 \pm 3.6 larvae were oviposited. Thus, the current results are in agreement with those of EL- Khouly, (2009). Other supporting results were reported by Patel et al.( 2005) who found that the parasitoid Diglyphus intermedius kills more hosts than it parasitizes . In an aearlier study (Heinz and Parrella (1990), it was observed that Diglyphus begini killed 1.3 L.trifolii larvae for every larva used for oviposition . 
Kassem, S. A. A. et al.

Fig. (1): Abundance of the ectoparasitoid D.isaea and percentage of parasitism in four tomato greenhouses, at Sakha Agricultural Research station, 2009 season

10702 
J. Agric. Sci. Mansoura Univ., 34 (11), November, 2009

T1

10703 


\section{REFERENCES}

Asadi, R.; A. A. Talebi; Y. Fathipour; S. Moharramipour and E. Rakhshani (2006). Identification of parasitoids and seasonal parasitism of agromyzid leaf miners genus Liriomyza (Dip: Agromyzidae) in Varamin. Iran. J. Agric. Sci. and Tech., 8(4): 293-303 .

Awadalla, S. S. and H. M .Fathy. (1998). Studies on hymenopterous parasitoids of the serpentine leaf miner, Liriomyza trifolii (Burgess) in Mansoura region. J .Agric. Mansoura Sci. Univ., 23 (12): 6257-6262 .

Awadalla, S. S.; L. M. Shanab*; A. I. Abd El-Kareim; M. S. El-Nagar and E. R. El-Khouly (2008). Host plant preference of the ectoparasitoid Diglyphus isaea Walker (Hymenoptera: Eulophidae). J. Agric. Mansoura Univ., 34 (1): 505-510.

Boucek, Z. and R. R. Askew (1968). Hym. Chalcidoidea. Palearctic. Eulophidae (excl. Tetrastichinae). Le Francois ,Paris.254pp

Baufled, P. and G. Motte (1992). On the biology and economic importance of Liriomyza trifolii (Burgess). Nachr Bl.dt.Pflschutzdenst, 44: 225-229.

El-Khouly, A. R. (2003). Studies on some natural enemies associated with the serpentine leaf miner Liriomyza trifolii (Burgess). M. Sc. Thesis, Fac., Agric., Mansoura univ. 116 pp.

El-Khouly, A. R. (2009). Efficiency of some hymenopterous parasitoids on serpentine leaf miner Liriomyza trifolii (Burgess). P h.D. Thesis, Fac., Agric., Mansoura univ. $185 \mathrm{pp}$.

Heinz, K. M. and M. P. Parrella (1990). Holarctic distribution of the leaf miner parasitoid Diglyphus begini (Hymenoptera : Eulophidae ) and notes of its life history attacking Liriomyza trifolii (Diptera : Agromyzidae ) in Chrysanthemum. Ann. Entomol. Soc. America, 83 (5):916-924.

Johnson, M. W. and A. H. Hara (1987). Influences of host crop on parasitoids (Hymenoptera) of Liriomyza spp. (Diptera: Agromyzidae). Environ. Entomol., 16:339-344 .

Linden, A. (1993). Biological control of leaf miners in glasshouse lettuce. "Liriomyza". Conference on leaf mining flies in cultivated plants. Montpellier- France ( March1993).

Spencer, K. A. (1973). Agromyzidae (Diptera) of economic importance Series. Entomol. 9: 1-4, Junk. The Hague.

Parrella, M. P. (1987). Biology of Liriomyza. Annu. Rev. Entomol., 32:301224.

Patel, K. J. ; D. J. Schuster and G. H. Smerage (2005) . Density dependant parasitism and host- killing of Liriomyza trifolii (Diptera : Agromyzidae ) by Diglyphus intermedius (Hymenoptera : Eulophidae) Fla . Entomol. 86: 8-14.

Ozawa, A.; T. Saito and M. Ota (2001). Biological control of the American serpentine leaf miner Liriomyza trifolii (Burgess) on Tomato in greenhouses by parasitoids. II- Evaluation of biological control by Diglyphus isaea (Walker ) and Dacnusa sibirica Telenga in commercial greenhouses. Jpn. J. Appl. Entomol. Zool., 45:61-74 . 
Ozawa, A.; T. Saito and M. Ota (1999). Biological control of American serpentine leaf miner Liriomyza trifolii (Burgess) on tomato in greenhouses by parasitoids. I. Evaluation of biological control by release of Diglyphus isaea (Walker) in experimental greenhouses. Jpn. Appl. Zool, 43:161-168.

Ozawa, A.; T. Saito and M. Ota (2001). Biological control of the American serpentine leaf miner Liriomyza trifolii (Burgess) on Tomato in greenhouses by parasitoids. II- Evaluation of biological control by Diglyphus isaea (Walker) and Dacnusa sibirica Telenga in commercial greenhouses. Jpn. J. Appl. Entomol. Zool., 45:61-74 .

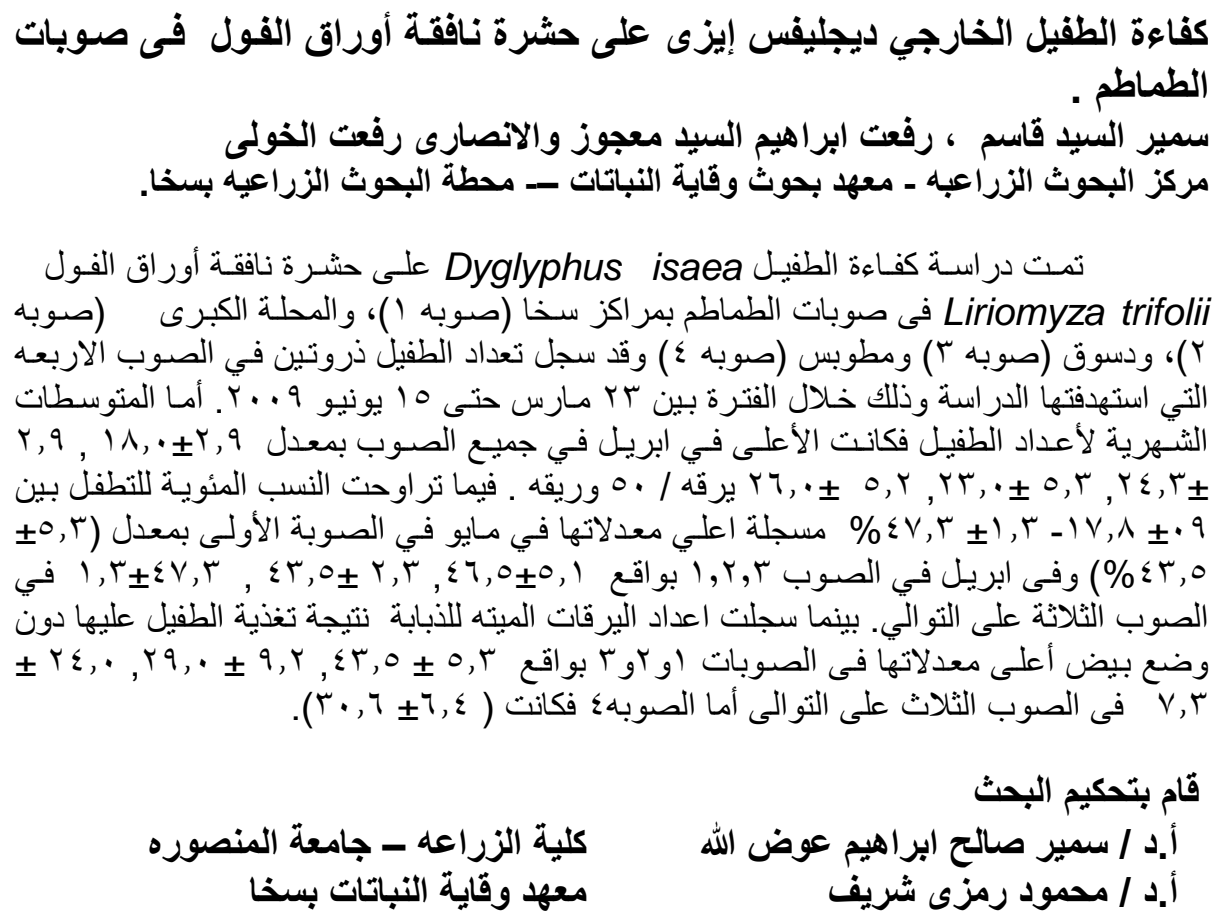

كلية الزراعه - جامعة المنصوره

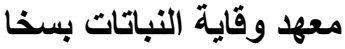


Table (1): Parasitism parameters of Diglyphus isaea on Liriomyza trifolii infesting tomato in greenhouses, Sakha Agricultural Research station, 2009 season.

\begin{tabular}{|c|c|c|c|c|c|c|c|c|c|c|c|c|}
\hline \multirow[b]{2}{*}{ Months } & \multicolumn{3}{|c|}{ Sakha(1) } & \multicolumn{3}{|c|}{ Mehalla AL- Kobra( 2 ) } & \multicolumn{3}{|c|}{ Desouk ( 3 ) } & \multicolumn{3}{|c|}{ Metobus( 4 ) } \\
\hline & 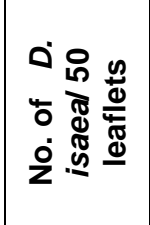 & 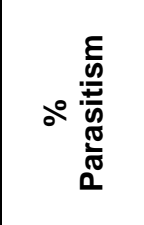 & 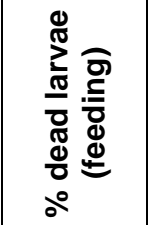 & 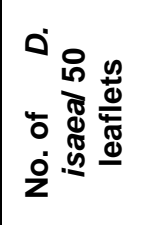 & 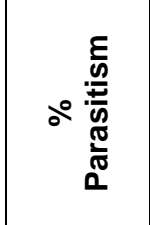 & 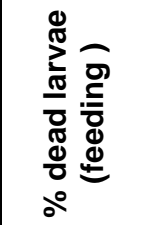 & 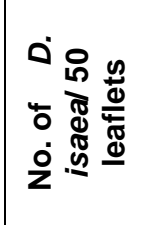 & 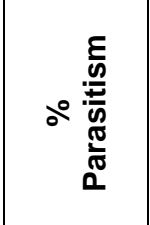 & 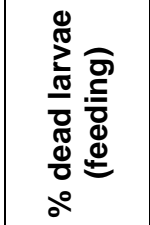 & 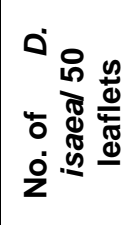 & ○位 & 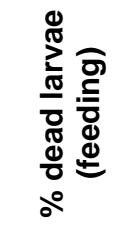 \\
\hline March & $8.0 \pm 2.8$ & $.9 \pm 6.8$ & $25.7 \pm 4.8$ & $20 \pm 4.2$ & $36.4 \pm 9.1$ & $20.7 \pm 1.0$ & $11.0 \pm 2.8$ & $32.6 \pm 2.7$ & $17.8 \pm 0.9$ & $8.5 \pm 3.5$ & $30.2 \pm 5.9$ & $19.6 \pm 3.2$ \\
\hline April & $18.0 \pm 2.9$ & $39.5 \pm 2.7$ & $29.9 \pm 4.1$ & $24.3 \pm 8.3$ & $46.4 \pm 5.1$ & $23.4 \pm 3.2$ & $23.0 \pm 5.2$ & $43.6 \pm 2.3$ & $22.9 \pm 5.0$ & $26.0 \pm 5.2$ & $47.3 \pm 1.3$ & $19.9 \pm 3.9$ \\
\hline May & $9.0 \pm 2.4$ & $27.5 \pm 2.4$ & $43.5 \pm 5.3$ & $8.8 \pm 3.4$ & $33.2 \pm 10.1$ & $29.0 \pm 9.2$ & $10.0 \pm 2.9$ & $33.3 \pm 6.4$ & $24.0 \pm 7.32$ & $14.3 \pm 5.9$ & $40.5 \pm 7.5$ & $22.5 \pm 8.3$ \\
\hline June & $9.6 \pm 3.1$ & $49.8 \pm 3.2$ & $23.6 \pm 13.5$ & $4.3 \pm 1.5$ & $32.1 \pm 17.1$ & $21.1 \pm 8.4$ & $5.7 \pm 0.6$ & $41.0 \pm 11.6$ & $3.6 \pm 3.2$ & $8.0 \pm 1.0$ & $38.1 \pm 18.3$ & $30.6 \pm 6.4$ \\
\hline lean \pm & $1.2 \pm 4$ & $36.9 \pm 10.0$ & $33.1 \pm 7.6$ & $11.6 \pm 8.7$ & $37.0 \pm 6.5$ & $23.6 \pm 3.8$ & $12.4 \pm 7.4$ & $37.6 \pm 5.5$ & $22.1 \pm 2.9$ & $14.2 \pm 8.4$ & $39.0 \pm 7.1$ & $23.1 \pm 5.1$ \\
\hline
\end{tabular}

